\title{
Vertical flux and degradation rates of copepod fecal pellets in a zooplankton community dominated by small copepods
}

\author{
Louise K. Poulsen*, Thomas Kiørboe \\ Danish Institute for Fisheries Research, Department of Marine Ecology and Aquaculture, Kavalergården 6, \\ 2920 Charlottenlund, Denmark
}

\begin{abstract}
Sediment trap studies have revealed that copepod fecal pellets can be degraded at high rates in the sea, and copepods, particularly of the order Cyclopoida, have been implicated as the main degraders of these fecal pellets. A field budget of copepod fecal pellet production, degradation and sedimentation was constructed from water column and sediment trap samples as well as from shipboard incubations during a $7 \mathrm{~d}$ late-summer period in the North Sea. In addition, fecal pellet degradation due to the activity of copepods and other zooplankton organisms $>200 \mu \mathrm{m}$ was estimated from shipboard experiments. The copepod community was dominated by the cyclopoid copepod Oithona similis. Only 3 to $39 \%$ of the fecal pellets produced in the upper $50 \mathrm{~m}$ of the water column were collected by sediment traps at $50 \mathrm{~m}$, corresponding to specific degradation rates of fecal pellets of 1 to $3 \mathrm{~d}^{-1}$. Accordingly, the fraction of suspended fecal pellets lost through sinking (sinking losses) and estimated pellet sinking velocities were low, and residence times short. Small fecal pellets were degraded at higher rates than larger fecal pellets. However, copepods and other zooplankton organisms $>200 \mu \mathrm{m}$ did not play an important role in the degradation of fecal pellets, since the estimated degradation due to zooplankton was 3 orders of magnitude lower than the total degradation rates of fecal pellets in the water column. This generally challenges the anticipated role of copepods in retarding the vertical flux of their own fecal pellets, and indicates that smaller plankton organisms $(<200 \mu \mathrm{m})$ have an important role in degrading fecal pellets in the sea.
\end{abstract}

KEY WORDS: Vertical flux $\cdot$ Fecal pellet $\cdot$ Degradation rate $\cdot$ Copepod $\cdot$ North Sea

\section{INTRODUCTION}

Zooplankton fecal pellets have long been considered a dominant component of vertical particle flux in the sea, because they are produced in large quantities and have high sinking velocities (Turner 2002). In the past decade, however, numerous field studies have shown that copepod fecal pellets often constitute only a minor portion of the vertical particle flux (Turner 2002). Copepod fecal pellets are thought to be degraded in the water column by microbes and by the copepods themselves through coprophagy (ingestion of pellets), coprorhexy (fragmentation of pellets) and coprochaly (loosening of pellets) (Lampitt et al.
1990, Noji et al. 1991, Turner 2002). Several copepod genera or species have been shown to degrade fecal pellets in the laboratory (Paffenhöfer \& Strickland 1970, Paffenhöfer \& Knowles 1979, Paffenhöfer \& Van Sant 1985, Ayukai \& Nishizawa 1986, Lampitt et al. 1990, Noji et al. 1991, González \& Smetacek 1994, González et al. 1994a). Thus, copepods may play an important role in reducing the vertical flux of fecal pellets in the field. However, the existing evidence for copepod degradation of fecal pellets in the field is circumstantial, and field estimates of actual degradation rates of fecal pellets by copepods do not exist. A negative correlation between the presence of copepods of the genus Oithona and fecal pellet material 
has been taken as evidence of a high coprophagous activity of Oithona spp. (González et al. 1994b). A low vertical flux of fecal pellets often corresponds to the dominance of small copepods in the water column (González \& Smetacek 1994, González et al. 1994a,b, Viitasalo et al. 1999, Wassmann et al. 2000, Svensen \& Nejstgaard 2003), suggesting that small copepods degrade fecal pellets at higher rates than large copepod species. However, this may as well be caused by the fact that small copepods produce small pellets, which have lower sinking velocities and are degraded faster than pellets produced by larger copepods (Poulsen \& Kiørboe 2005).

The aim of this study was to investigate production, abundance, vertical flux and degradation rate of copepod fecal pellets in the field, and specifically to examine the importance of copepods and other large zooplankton in the degradation of fecal pellets.

\section{MATERIALS AND METHODS}

Sampling and location. Sampling and experiments were conducted in the northern North Sea from 7 to 14 August 2002 at water depths between 56 and $58 \mathrm{~m}$ (Fig. 1). Sampling was conducted while following a drifting buoy equipped with an ARGOS satellite transmitter and a sediment trap array. The buoy was deployed close to the amphidromic point in the North Sea, i.e. the place of minimum tidal currents, to minimize the influence of currents on the capture efficiency of the trap array. The buoy station was sampled once per day from 7 to 14 August and additionally every 6 to $8 \mathrm{~h}$ during two $24 \mathrm{~h}$ time studies on 9 to 10 and 13 to 14 August (Table 1). Sampling was at 10, 20, 30, 40 and $50 \mathrm{~m}$ depth at all stations.

Hydrography and phytoplankton. Continuous vertical profiles of temperature, salinity and fluorescence

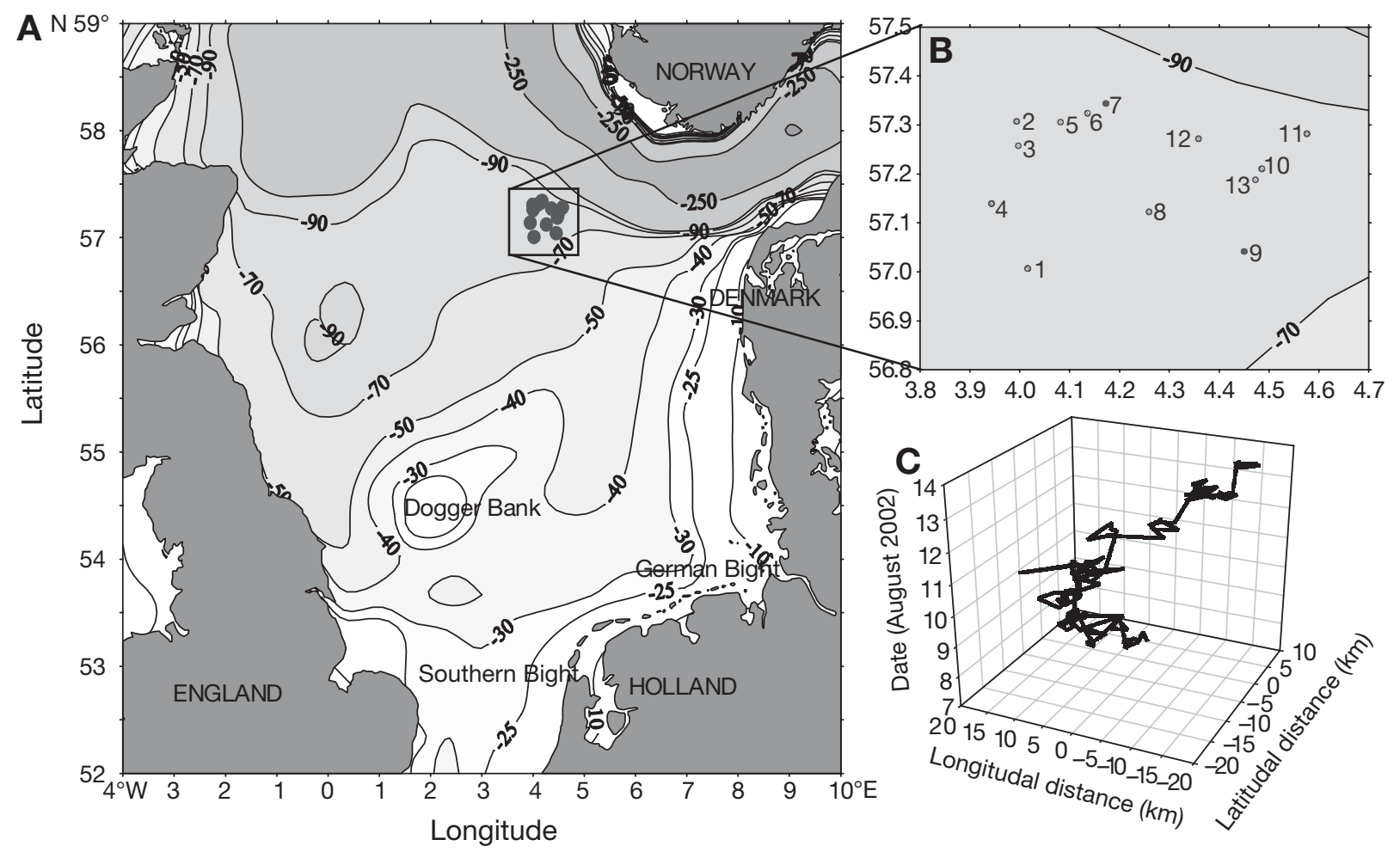

Fig. 1. (A) Study area in North Sea; sediment trap stations (๑). (B) Magnification of study area with stations numbered according to sampling order. (C) 3D-plot of drift track of buoy during deployment

Table 1. Sampling data. Station locations indicated on Fig. 1. Sampling was conducted in August 2002 and time is GMT. The 2 time studies are indicated with gray boxes

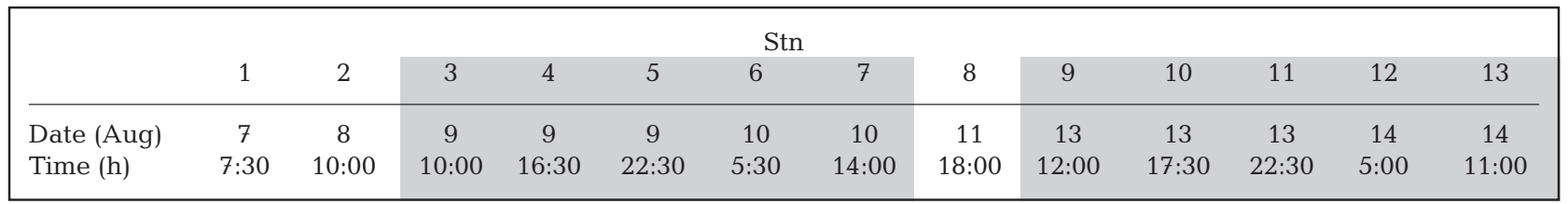


were recorded at each station using a SeaBird SBE11 CTD equipped with an in situ fluorometer. The fluorometer was calibrated against spectrophotometrical measures of extracted chlorophyll a ( $\mathrm{chl} a$ ) in discrete water samples collected during the cruise. Phytoplankton composition was assessed qualitatively using an inverted microscope in water samples collected from the surface water, the pycnocline, and the bottom layer at selected stations. Wind speed was measured continuously and logged at 5 min intervals.

Zooplankton abundance $(\boldsymbol{C})$ and identification. Zooplankton was sampled at each station and depth by a zooplankton pump ( 1200 $\left.1 \mathrm{~min}^{-1}\right)$ equipped with a $55 \mu \mathrm{m}$ net and a closed cod end. The sampling efficiency of the zooplankton pump is comparable to that of the WP-2 net (Møhlenberg 1987). Each sample consisted of 0.6 to $4.3 \mathrm{~m}^{3}$. The samples were preserved with Borax buffered formalin $(10 \%$ final concentration). Zooplankton were identified and counted in subsamples (using a box-splitter), such that counts were $>200$ for each of the major copepod species. Copepods were identified to species and developmental stage when possible, and prosome lengths were measured.

Pellet abundance $(\boldsymbol{F})$. Water samples for enumeration of fecal pellets were obtained with a rosette water sampler equipped with 51 Niskin bottles. Approximately $10 \mathrm{l}$ from each depth were filtered trough a $15 \mu \mathrm{m}$ screen and the retained material was preserved in acid Lugol's solution (2\% final concentration).

Vertical flux $(\boldsymbol{J})$. Vertical flux of fecal pellets was estimated through $24 \mathrm{~h}$ deployments of a free-drifting sediment trap array. The trap array consisted of 2 cylindrical trap tubes suspended every $10 \mathrm{~m}$ between 10 and $50 \mathrm{~m}$. The attachment to the trap line was gimballed and the drag force was equal above and below the pivot point, with the center of gravity situated near the bottom of the cylinders (Olesen 2001). The tubes had an inner diameter of $5.2 \mathrm{~cm}$ and an aspect ratio of 5.7. Prior to deployment, the trap tubes were filled with $0.2 \mu \mathrm{m}$ filtered bottom water, to which salt was added (final salinity: 37 ) and acid Lugol's solution (1\% final concentration). The salinity varied little between 0 and $60 \mathrm{~m}$ (34.9 to 35.1 psu, see Fig. 2), thus minimizing the problem of differential sampling efficiency between depths. Upon retrieval of the traps, the top $10 \mathrm{~cm}$ content of the trap tubes was removed and the residual filtered through a $15 \mu \mathrm{m}$ screen; the retained material was preserved for later enumeration of the fecal pellets. Very few copepods were found in the trap tubes $(12 \pm 5$, average $\pm \mathrm{SD})$. Thus, the potential problem of 'swimmer' contamination through emptying of the copepods' guts when entering the preserved traps was minimal (Peterson \& Dam 1990).

Pellet production $(\boldsymbol{p})$. To estimate fecal pellet production, an assemblage of copepods and other zoo- plankton were incubated onboard, in dim light, and at a temperature corresponding to the temperature at the depth of the fluorescence maximum. The zooplankton for incubation experiments was collected by a vertical haul with a $200 \mu \mathrm{m}$ mesh size WP-2 net from 50 to $0 \mathrm{~m}$. The cod end contents were diluted to $\sim 101$ and subsamples of $50 \mathrm{ml}$ immediately transferred to each of 3 plastic cylinders $(25 \times 14 \mathrm{~cm})$ with bottoms consisting of $300 \mu \mathrm{m}$ plankton mesh. The cylinders were submerged into 51 jars containing water from the fluorescence maximum depth. After $2 \mathrm{~h}$ incubation, the jar content was filtered through a $15 \mu \mathrm{m}$ screen, and retained fecal pellets were preserved in acid Lugol's solution and counted. We conducted 1 experiment at each station. The viability of the zooplankton was controlled before use in the experiments and no significant number of dead animals was observed after incubation. Coprophagy was kept at a minimum during incubation by using a bottom mesh and a low copepod concentration $\left(\sim 34\right.$ to 109 copepods $\left.\mathrm{l}^{-1}\right)$. The optimal copepod concentration was obtained by running several incubations with varying copepod concentrations to determine at which concentration the maximum number of pellets were produced per animal. The copepods were not counted in the production experiments, but extrapolated from the copepod counts in the coprophagy experiments.

The fecal pellet production was calculated from the number of pellets produced in the incubations while taking into account the subsample volume incubated of the total volume sampled by the net haul:

$$
p C=\frac{(\text { pellets } / t) / V_{\text {total }}}{V_{i} / V_{d}} \times 24 \mathrm{~h}
$$

where $p C$ (pellets $\mathrm{m}^{-2} \mathrm{~d}^{-1}$ ) is pellet production, pellets is the number of pellets produced in the incubation, $t$ (h) is time, $V_{\text {total }}\left(\mathrm{m}^{3}\right)$ is the total volume sampled by the net haul, $V_{i}(\mathrm{l})$ is the volume of the subsample, and $V_{d}$ (l) is the volume of the diluted cod end content.

Coprophagy experiment $\left(\boldsymbol{r}_{2}\right)$. At each station, 5 dilutions of zooplankton from the vertical net haul $(10,25,75,175$ and $250 \mathrm{ml}$ of the $10 \mathrm{l}$ cod end contents diluted to 1.2 l) were incubated in triplicate in 1.21 bottles. The bottles contained water from the fluorescence maximum depth $(\sim 30 \mathrm{~m})$ and additionally $10 \mathrm{ml}$ of Thalassiosira weissflogii culture (100000 to 300000 cells $\mathrm{ml}^{-1}$ culture) to insure a saturating food concentration. A saturating food concentration was necessary to insure a constant pellet production, which was assumed in the calculations (see subsection 'Calculations' below). The bottles were mounted on a plankton wheel (1.5 rpm) and kept in darkness at $10^{\circ} \mathrm{C}$. This temperature was used to approximate the in situ temperature in fluorescence maximum. After $5 \mathrm{~h}$ incubation, the contents were filtered onto a 
$15 \mu \mathrm{m}$ screen and the retained material preserved in acid Lugol's solution for later enumeration of fecal pellets and copepods. Coprophageous degradation of fecal pellets was estimated by fitting the fecal pellet and copepod concentrations (varying from 69 to 3365 copepods $\mathrm{l}^{-1}$ ) in the incubation bottles at the end of incubation to Eq. (3) as described in subsection 'Calculations' below.

Counting. All fecal pellet samples were enumerated using an inverted microscope (Nikon Diaphot 300) with ocular micrometer. The pellets were counted in size categories of $50 \mu \mathrm{m}$ according to the length of the pellet or the fragments. In each of the resulting 14 size categories, the length and width of 10 to 20 pellets were recorded and the fecal pellet volumes were calculated using appropriate stereometrical configurations (Edler 1979). The total number of pellets in each sample was estimated by counting each fragment as a half pellet. Only end pieces or fragments recognizable as a half pellet were counted.

Pellet-copepod size relation. Fecal pellets were produced in incubation experiments with individual species collected from the net hauls (Oithona similis, Microsetella norvegica, Calanus spp., Paracalanus parvus, Temora longicornis) or from a laboratory culture (Acartia tonsa). The animals were incubated in water from the fluorescence maximum depth with an addition of Thalassiosira weissflogii culture to ensure saturating food concentrations. Fecal pellets were produced in incubations of either a single animal (O. similis, M. norvegica and Calanus spp.) or different stages of one species (Calanus spp., P. parvus, Temora longicornis, A. tonsa). In incubations of several animals, copepod prosome lengths and $>100$ pellets were measured.

Calculations. Specific loss rates $\left(s+r_{1}\right)$, sinking losses $(s$, the fraction of suspended fecal pellets lost through sinking) and degradation rates $\left(r_{1}\right)$ of fecal pellets were estimated from observed production rates $(p C)$, abundances $(F)$, and vertical fluxes $(J)$ of fecal pellets using the model of (Kiørboe 2003):

$$
F=\frac{p C}{s+r_{1}} \text { and } s=\frac{J}{F} \Rightarrow r_{1}=\frac{p C-J}{F}
$$

where $F$ (pellets $\mathrm{m}^{-2}$ ) is the fecal pellet abundance integrated from 0 to $50 \mathrm{~m}, C$ (copepods $\mathrm{m}^{-2}$ ) is the copepod abundance integrated from 0 to $50 \mathrm{~m}, p$ (pellets ind..$^{-1} \mathrm{~d}^{-1}$ ) is the specific pellet production rate as measured in incubation experiments, $J$ (pellets $\mathrm{m}^{-2}$ $\left.\mathrm{d}^{-1}\right)$ is the pellet flux at $50 \mathrm{~m}, r_{1}\left(\mathrm{~d}^{-1}\right)$ is the total degradation rate of pellets, and $s\left(\mathrm{~d}^{-1}\right)$ is the specific sinking loss. The residence time (d) of pellets in the water column is estimated as $R=F / p C$. This approach assumes steady state. Finally, pellet sinking velocity was computed as $S=J / F F$, where $F F$ (pellets $\mathrm{m}^{-3}$ ) is pellet concentration at $50 \mathrm{~m}$.

Fecal pellet degradation due to the feeding activity of zooplankton retained by the $200 \mu \mathrm{m}$ net was estimated from the fecal pellet and copepod concentrations at the end of the incubation in the coprophagy experiment, assuming constant pellet production and pellet degradation rates during the course of the incubations (Poulsen \& Kiørboe 2005):

$$
\begin{gathered}
C_{P}(n)=\frac{p}{f_{P}}\left(1-\exp ^{-\left(r_{2} \times n\right)}\right) \\
r_{2}=f_{p} \times t
\end{gathered}
$$

where $C_{P}$ (pellets $\mathrm{l}^{-1}$ ) is the final pellet concentration in the incubation bottle as a function of the concentration of copepods, $n$ (copepods $\mathrm{l}^{-1}$ ) is the copepod concentration in the bottle, $p$ (pellets ind..$^{-1} \mathrm{~h}^{-1}$ ) is the specific pellet production rate, $r_{2}\left(\mathrm{~h}^{-1}\right)$ is the degradation rate of fecal pellets due to coprophagy, $f_{p}\left(l\right.$ ind..$\left.^{-1} \mathrm{~h}^{-1}\right)$ is the specific pellet clearance rate, and $t(\mathrm{~h})$ is the incubation time. Eq. (3) was fitted to plots of fecal pellet concentration as a function of copepod concentration, and the parameters $\left(p, f_{P}\right)$ estimated. Fecal pellets produced by nauplii were not included in the pellet counts and the number of nauplii is therefore excluded from the calculations.

Statistics. The flux loss, sinking velocity, specific sinking loss, residence time and total degradation rate $\left(r_{1}\right)$ estimated from either pellet numbers or pellet volume were compared by Student's $t$-tests. Fecal pellet equivalent spherical diameter (ESD) and fecal pellet abundances, production and flux from the two $24 \mathrm{~h}$ time studies were compared by Student's $t$-tests (abundance, production and flux samples). The influence of depth on pellet size, concentration and flux was investigated by 2-way ANOVAs, using station and depth as factors. The flux loss, sinking velocity, specific sinking loss, residence time and total degradation rate $\left(r_{1}\right)$ computed from both fecal pellet numbers and pellet volumes were also compared by Student's $t$-tests.

\section{RESULTS}

\section{Hydrography and phytoplankton}

The buoy drifted within an area of $16 \mathrm{~km}^{2}$ (Fig. 1), all the time following the same water masses, as revealed by approximately uniform water column characteristics throughout the study period. Low wind speed (average $5 \mathrm{~m} \mathrm{~s}^{-1}$ ) and high solar radiation before and during the first part of the study period caused a highly stable water column, with a thermo- 


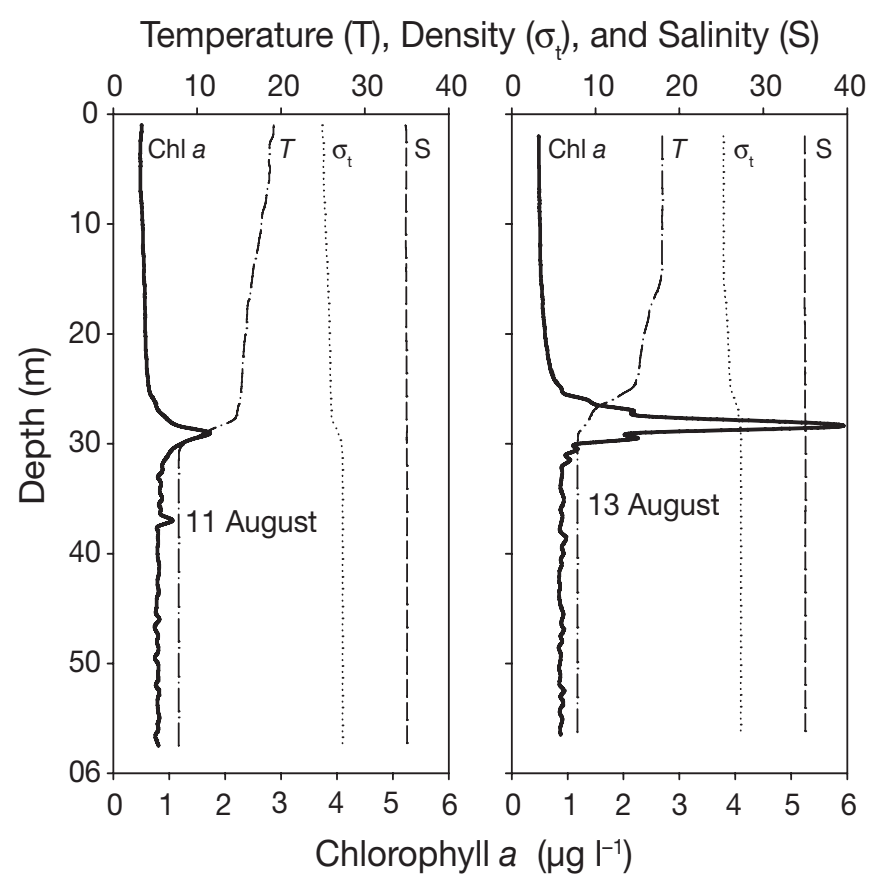

Fig. 2. Hydrography. Vertical distribution of chlorophyll (from fluorescence), temperature $\left({ }^{\circ} \mathrm{C}\right)$, density and salinity on 11 and 13 August 2002, before and after wind event

cline at 15 to $30 \mathrm{~m}$ depth separating $\sim 18^{\circ} \mathrm{C}$ surface water from $8^{\circ} \mathrm{C}$ bottom water (Fig. 2). The water column was almost vertically isohaline, with salinities ranging from 34.9 to $35.1 \mathrm{psu}$. The fact that the trap did not travel very far and the homogeneity of the water column at the stations indicated that the trap was only influenced by low currents. Thus, the capture efficiency of the trap was likely to have been good during the cruise.

Chl a concentrations were generally low except for a subsurface maximum $\left(\sim 1\right.$ to $\left.7 \mu \mathrm{g} \mathrm{chl} \mathrm{a} \mathrm{l}^{-1}\right)$ in the lower part of the thermocline between 25 and $30 \mathrm{~m}$. The phytoplankton community was typical for a late summer/autumn situation, with a diverse species composition dominanted by large autotrophic/mixotrophic dinoflagellates such as Ceratium furca, C. fusus, C. horridum and the diatom Proboscia alata in the pycnocline, and smaller flagellates in the upper mixed layer.

Following a wind event $\left(12 \mathrm{~m} \mathrm{~s}^{-1}\right)$ on 12 August, the chl a concentration in the fluorescence maximum increased from $\sim 2 \mu \mathrm{g} \mathrm{chl} \mathrm{a} \mathrm{l}^{-1}$ on 11 August to $6 \mu \mathrm{g} \mathrm{chl} \mathrm{a}$ $\mathrm{l}^{-1}$ on 13 August (Fig. 2). Correspondingly, the depthintegrated chl a concentration increased from $39 \pm$ $3 \mathrm{mg}$ chl a m${ }^{-2}$ during Time Study 1 (9 to 10 August) to $64 \pm 27 \mathrm{mg} \mathrm{chl} \mathrm{a} \mathrm{\textrm {m } ^ { - 2 }}$ during Time Study 2 (13 to 14 August) (Fig. 3). The wind event did not induce a change in water masses (temperature/salinity,

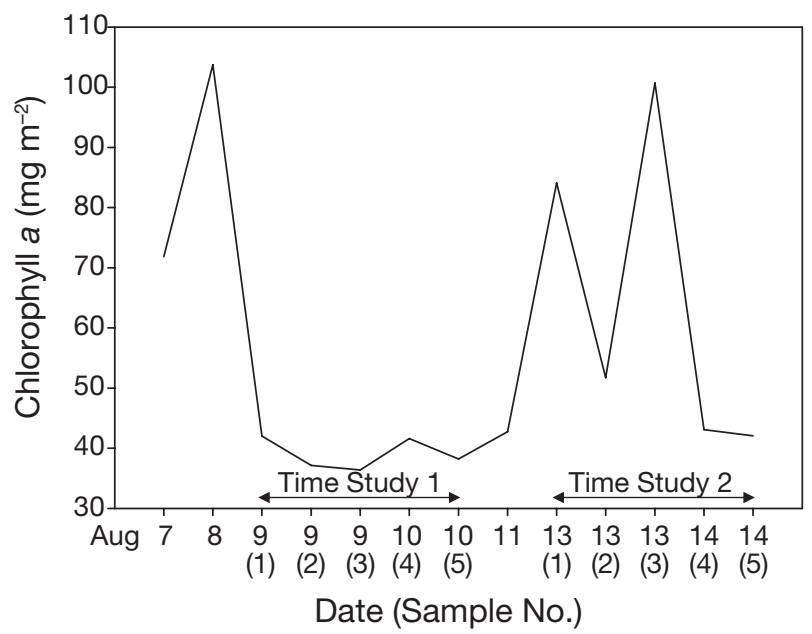

Fig. 3. Integrated $\mathrm{chl}$ a concentration $\left(\mathrm{mg} \mathrm{m}^{-2}\right)$ at buoy station during study period; $X$-axis gives sampling date in August and (in time studies) sampling number in parentheses. Sampling times 1 to 5 in Time Study 1 were 10:00, 16:30, 22:30, 05:30 and 14:00 h, respectively, and in Time Study 2 were 12:00, $17: 30,22: 30,05: 00$ and 11:00 $h$, respectively

T/S-diagrams not shown) nor a shift in the phytoplankton community.

\section{Zooplankton abundance}

Depth-integrated copepod abundance and species composition varied little during the study (Table 2, Fig. 4A). Oithona spp. copepodites and adult O. similis dominated numerically, except on 7 August, when Microsetella norvegica was equally abundant (Fig. 4A). The remaining zooplankton ('Other zooplankton': Fig. 4) was dominated by echinoderms (average $8 \times 10^{4}$ ind. $\mathrm{m}^{-2}$ ), bivalves (average $8 \times 10^{4}$ ind. $\mathrm{m}^{-2}$ ), Gastropods (average $5 \times 10^{4}$ ind. $\mathrm{m}^{-2}$ ) and polychaete larvae (average $1 \times 10^{4}$ ind. $\mathrm{m}^{-2}$ ). Vertically, both copepods and other zooplankton were most abundant in the upper mixed layer (Fig. 4B). The zooplankton generally did not migrate vertically, with a few exceptions such as Metridia lucens and $O$. pluminifera, which migrated approximately $10 \mathrm{~m}$ during the day. Sampling time did not influence the abundance of copepods, other zooplankton, or nauplii (Fig. 4A).

\section{Fecal pellets}

The field budget in Table 2 is estimated from the fecal pellet numbers in production, abundance and flux samples. Also, the fecal pellet volume of production, abundance and flux samples are presented in the table (gray box in Table 2). The flux loss, sinking 
Table 2. Field budget of fecal pellets in North Sea in August 2002. All values are presented as $24 \mathrm{~h}$ averages of samples collected during each deployment of sediment trap. Sediment trap was deployed for $24 \mathrm{~h}$, except for 5th deployment (11 to 13 August), when trap was left for $48 \mathrm{~h}$ due to a wind event (WE) on 12 August

\begin{tabular}{|c|c|c|c|c|c|c|}
\hline \multirow[t]{2}{*}{ Parameter } & \multicolumn{6}{|c|}{ Deployment No. (period, Aug 2002) } \\
\hline & $\begin{array}{c}1 \\
(7-8)\end{array}$ & $\begin{array}{c}2 \\
(8-9)\end{array}$ & $\begin{array}{c}3 \\
(9-10)\end{array}$ & $\begin{array}{c}4 \\
(10-11)\end{array}$ & $\begin{array}{c}\text { 5, WE } \\
(11-13)\end{array}$ & $\begin{array}{c}6 \\
(13-14)\end{array}$ \\
\hline Chlorophyll a (mg chl a m-2) & 88 & 73 & 39 & 40 & 63 & 64 \\
\hline Copepod abundance, $C\left(10^{4} \times \text { ind. } \mathrm{m}^{-2}\right)^{\mathrm{a}}$ & 19 & 17 & 19 & 17 & 19 & 20 \\
\hline Production, $p C\left(10^{9} \times \mu \mathrm{m}^{3} \mathrm{~m}^{-2} \mathrm{~d}^{-1}\right)^{\mathrm{b}}$ & 114 & 239 & 415 & 661 & 458 & 133 \\
\hline Abundance, $F\left(10^{9} \times \mu \mathrm{m}^{3} \mathrm{~m}^{-2}\right)^{\mathrm{b}}$ & 79 & 92 & 155 & 179 & 126 & 68 \\
\hline Flux, $J\left(10^{9} \times \mu \mathrm{m}^{3} \mathrm{~m}^{-2} \mathrm{~d}^{-1}\right)^{\mathrm{b}}$ & 85 & 151 & 249 & 148 & 13 & 10 \\
\hline Production, $p C\left(10^{4} \times\right.$ pellets $\left.\mathrm{m}^{-2} \mathrm{~d}^{-1}\right)$ & 30 & 95 & 136 & 174 & 158 & 77 \\
\hline Abundance, $F\left(10^{4} \times\right.$ pellets $\left.\mathrm{m}^{-2}\right)$ & 22 & 41 & 64 & 56 & 73 & 60 \\
\hline Flux, $J\left(10^{4} \times\right.$ pellets $\left.\mathrm{m}^{-2} \mathrm{~d}^{-1}\right)$ & 12 & 24 & 49 & 17 & 5 & 7 \\
\hline Flux/Production, $J / p C \times 100(\%)$ & 39 & 25 & 36 & 10 & 3 & 9 \\
\hline Sinking velocity, $S\left(\mathrm{~m} \mathrm{~d}^{-1}\right)$ & 21 & 16 & 25 & 13 & 2 & 4 \\
\hline Residence time, $R(\mathrm{~d})$ & 0.7 & 0.4 & 0.5 & 0.3 & 0.5 & 0.8 \\
\hline Specific sinking loss, $s\left(\mathrm{~d}^{-1}\right)$ & 0.5 & 0.6 & 0.8 & 0.3 & 0.1 & 0.1 \\
\hline Total degradation rate, $r_{1}\left(\mathrm{~d}^{-1}\right)$ & 0.9 & 1.7 & 1.4 & 2.8 & 2.1 & 1.2 \\
\hline Degradation rate due to zoopl. $>200 \mu \mathrm{m}, r_{2}\left(\mathrm{~d}^{-1}\right)$ & $\sim 0$ & $\sim 0$ & $\sim 0$ & 0.002 & 0.001 & 0.001 \\
\hline \multicolumn{7}{|c|}{$\begin{array}{l}\text { aZ Zooplankton collected by a vertical net haul from } 50 \text { to } 0 \mathrm{~m} \text { (mesh size }=200 \mu \mathrm{m}) \\
\text { 'Production, abundance and flux are presented both as pellet numbers and as pellet volume. Flux loss, sinking velocity, spe- } \\
\text { cific sinking loss, residence time and total degradation rate }\left(r_{1}\right) \text { were calculated from pellet numbers; however, estimates } \\
\text { were not significantly different when calculated from either pellet numbers or volume (Student's } t \text {-tests). } \sim 0 \text { : estimated } \\
\text { degradation rate was not significantly different from } 0\end{array}$} \\
\hline
\end{tabular}
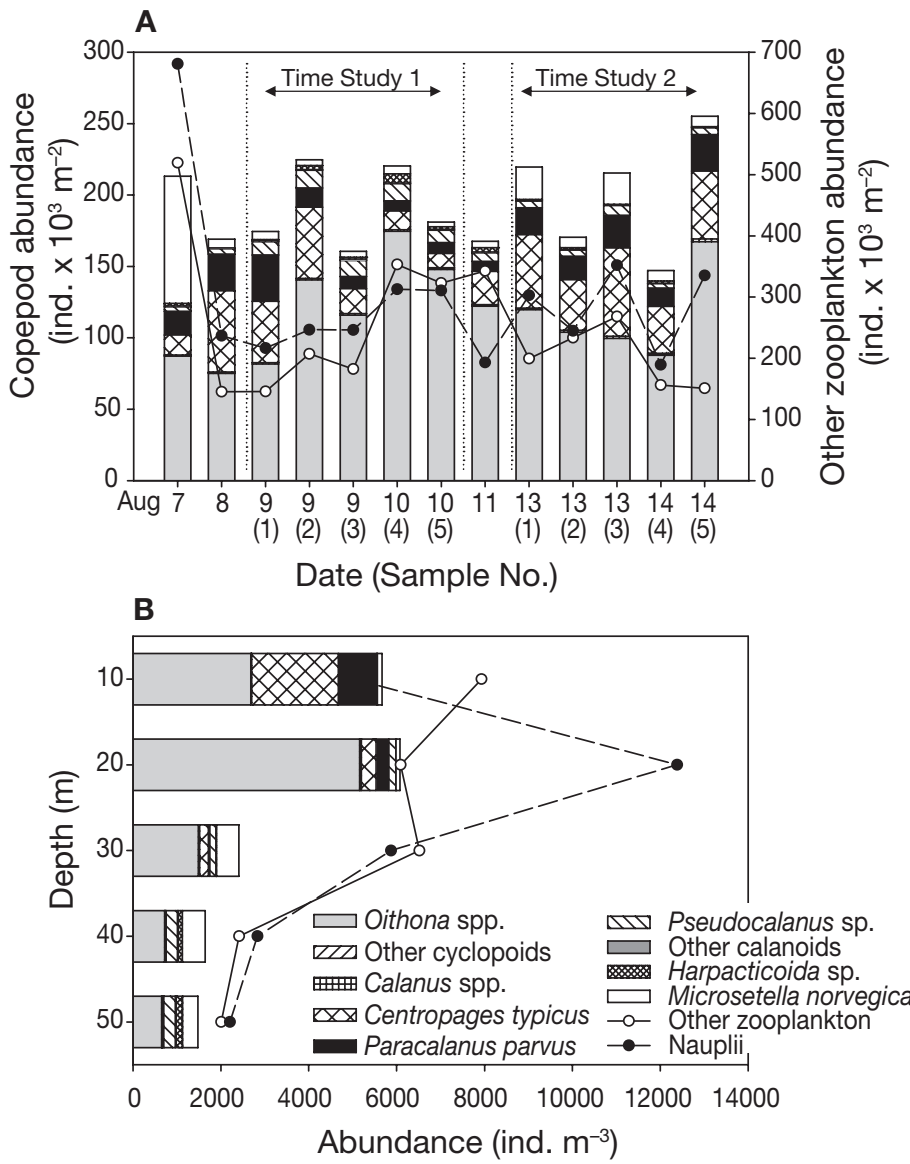

Fig. 4. Abundance of copepods and other zooplankton. (A) Integrated abundance $(0$ to $50 \mathrm{~m})$ as a function of sampling time; $x$-axis as in Fig. 3. (B) Vertical distribution of average abundances (average for all stations) velocity, specific sinking loss, residence time and total degradation rate $\left(r_{1}\right)$ were computed from both fecal pellet numbers and pellet volumes, and the 2 sets of estimates did not differ significantly $(p>0.05$; $t$-test).

Average fecal pellet production during each sediment trap deployment ranged from 30 to $174 \times 10^{4}$ pellets $\mathrm{m}^{-2} \mathrm{~d}^{-1}$ (Table 2), equivalent to a per capita production of 2 to 10 pellets copepod $\mathrm{d}^{-1} \mathrm{~d}^{-1}$. The average pellet production was highest during Deployments 3 to 5 (Table 2). The two $24 \mathrm{~h}$ time studies showed a general tendency toward maximum pellet production around noon (Time Studies 1 and 2, Sample Nos 1 and 5) and a minimum around midnight (Time Studies 1 and 2, Sample No. 3) (Fig. 5A). The temporal variation in fecal pellet abundance and flux largely followed the variation in pellet production, but with a slight time lag in pellet abundance relative to production (Fig. 5A). The fecal pellet abundances averaged for each deployment period varied (22 to $73 \times 10^{4}$ pellets $\mathrm{m}^{-2}$ ) (Table 2 ) and the $24 \mathrm{~h}$ time studies revealed variation during the day similar to that observed for fecal pellet production (Fig. 5A). Depth influenced the number and size of fecal pellets significantly in both abundance and sediment trap samples $(p<0.05)$. Generally, the number of fecal pellets in both types of samples increased with increasing depth, whereas the average size (ESD) of the pellets reached a maximum at $30 \mathrm{~m}$, corresponding to the depth at which the large Calanus species were most abundant.

The vertical flux of fecal pellets was low compared to the pellet production throughout the study period, es- 

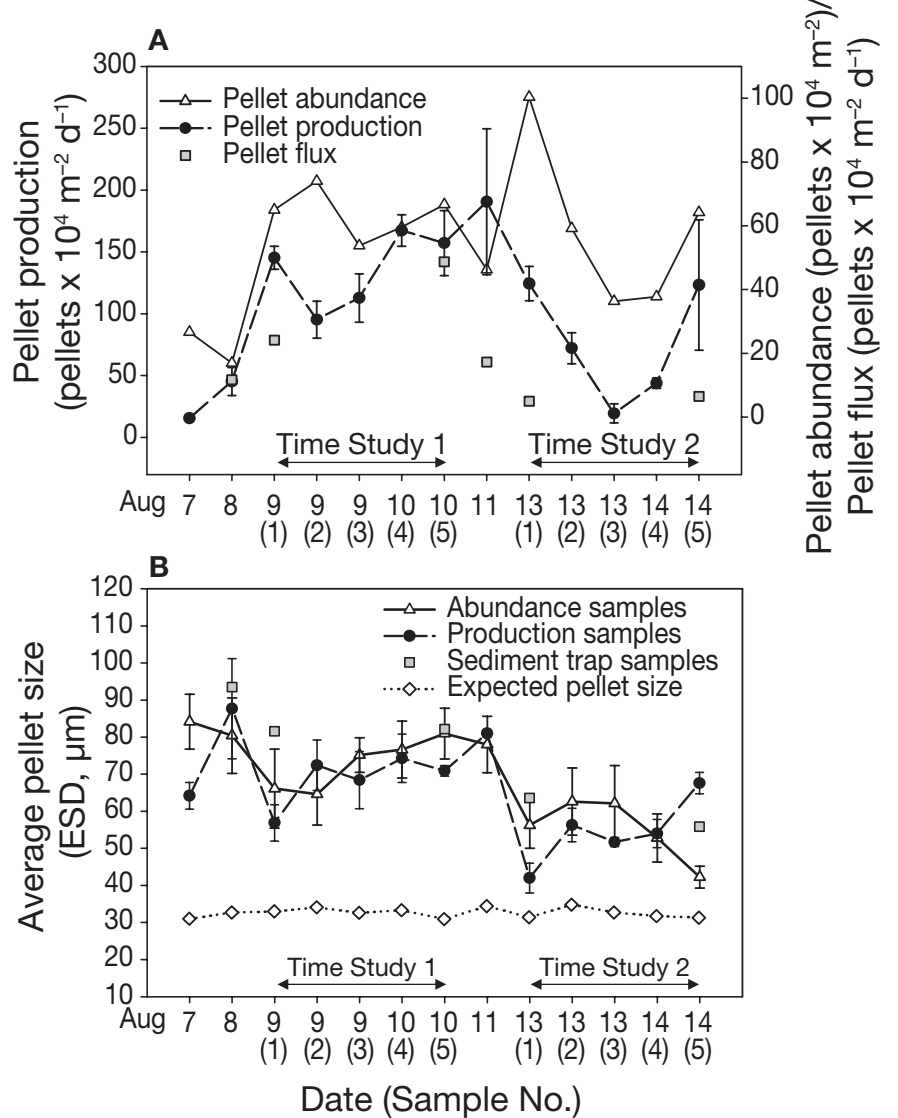

Fig. 5. Fecal pellet numbers and sizes. (A) Integrated (0 to $50 \mathrm{~m}$ ) fecal pellet production, abundance and flux; SD for production calculated from triplicate incubations. (B) Average pellet size in fecal pellet samples and expected average pellet size estimated from observed average prosome lengths $(\mu \mathrm{m})$ of copepods and the relationship in Fig. 6; SD estimated from average ESD in triplicate incubations for production and the 5 sampling depths of pellet abundance; $x$-axis as in Fig. 3

pecially during the last 2 deployments after the wind event (Table 2, Fig. 5A). Thus, only 3 to $39 \%$ of the fecal pellets produced in the upper $50 \mathrm{~m}$ of the water column were collected in the $50 \mathrm{~m}$ trap (Table 2), suggesting a high degree of degradation of fecal pellets in the water column. This was supported by high estimates of total degradation rates $\left(r_{1}\right)$ of fecal pellets of between 1 and $3 \mathrm{~d}^{-1}$ (Table 2). Copepods and mesozooplankton in general did not play an important role in the degradation of the fecal pellets. This was apparent in the low estimated degradation rates arising from zooplankton $>200 \mu \mathrm{m}\left(r_{2}\right.$, coprophagy experiments $)$, which were 3 orders of magnitude lower than the estimated total degradation rates of fecal pellets in the water column $\left(r_{1}\right)$ (Table 2). Fecal pellet clearance rates obtained from the coprophagy experiments were also low, ranging from 3 to $8 \mathrm{ml}$ copepod $^{-1} \mathrm{~d}^{-1}$. In accordance with this, there was no correlation between the total degradation

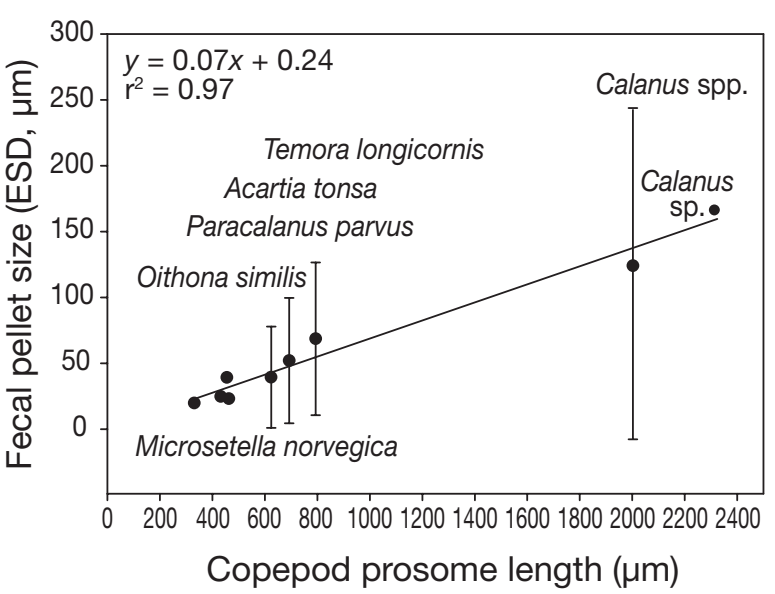

Fig. 6. Relationship between copepod prosome length and pellet size measured in on board ship laboratory experiments with natural plankton. Fecal pellets were produced during incubation of either single individual (Oithona similis, Microsetella norvegica and Calanus sp.) or different stages of 1 species (Acartia tonsa, Calanus spp., Paracalanus parvus, Temora longicornis); in latter case, average ESD \pm SD of $>100$ pellets is given

rate $\left(r_{1}\right)$ and copepod abundance or the abundance of any single copepod species. Corresponding to the high total degradation in the water column, estimated sinking velocities and sinking losses were low and residence time generally short during the study (Table 2).

Fecal pellets produced by various species/stages of copepods revealed a linear relationship between copepod prosome length and the equivalent spherical diameter (ESD) of the fecal pellets produced (Fig. 6). The average size (average ESD $\pm \mathrm{SD}$ ) of the fecal pellets in production samples $(65 \pm 13 \mu \mathrm{m})$ was similar to that of pellets collected in the water column $(63 \pm$ $14 \mu \mathrm{m})$, while pellets caught in the traps were larger $(80 \pm 18 \mu \mathrm{m})$. A change toward smaller fecal pellets was observed between the first and the second $24 \mathrm{~h}$ time study, since fecal pellets were significantly smaller in production $(p=0.02, t$-test $)$, abundance $(p<$ $0.001, t$-test) and flux ( $\mathrm{p}<0.001, t$-test) samples during Time Study 2 after the wind event than during Time Study 1 (Fig. 5B). However, the expected fecal pellet size, estimated from the average copepod prosome lengths at each sampling and assuming a pellet production rate independent of copepod size, was constant throughout the study and much lower $(33 \pm 1 \mu \mathrm{m})$ than the observed pellet sizes (Fig. 5B). The change toward smaller pellets in the second $24 \mathrm{~h}$ study after the wind event corresponded to a pronounced lowering of the pellet flux, sinking rate and specific sinking loss by a factor of 5 (Table 2). The change toward smaller pellets also resulted in a slight increase in the residence time of the fecal pellets (Table 2). 


\section{DISCUSSION}

\section{Role of copepods in reducing vertical flux of fecal pellets}

The majority of the fecal pellets produced in the study area were degraded within the upper $50 \mathrm{~m}$ of the water column, resulting in high total degradation rates and a low vertical flux. A high degradation of fecal pellets in the upper water layer of the North Sea has also been observed by Martens \& Krause (1990). A low flux of fecal pellets is a typical observation in both neritic and more oceanic regions of the ocean (Smetacek 1980, Roman \& Gauzens 1997, Viitasalo et al. 1999, Sampei et al. 2004), especially when the zooplankton community is dominated by small copepods (González \& Smetacek 1994, Svensen \& Nejstgaard 2003). González \& Smetacek (1994) showed that at cyclopoid:Calanus spp. ratios $>0.3$ the residence time of calanoid fecal pellets increased significantly, and at ratios $>4$ almost all calanoid pellets were degraded in the water column. These results fit in well with those of this study, in which cyclopoid:Calanus spp. ratios of 0.9 to 2.1 corresponded to a high degradation of fecal pellets in the water column (61 to $97 \%$ ). Observations of this kind have led to the general belief that copepods are among the main degraders of copepod fecal pellets, and this has been supported by high fecal pellet clearance rates measured in the laboratory for some species such as Eucalanus pileatus and Temora stylifera (Paffenhöfer \& Knowles 1979, Paffenhöfer \& Van Sant 1985). However, direct evidence from field studies is lacking.

Incubations of zooplankton caught by the $200 \mu \mathrm{m}$ net in this study (coprophagy experiments) resulted in low fecal pellet degradation and fecal pellet clearance rates (3 to $8 \mathrm{ml} \mathrm{copepod}^{-1} \mathrm{~d}^{-1}$ ). Thus, despite high total degradation rates, copepods and other zooplankton $>200 \mu \mathrm{m}$ had little impact on the fecal pellets.

Estimates of fecal pellet degradation and clearance obtained in the coprophagy experiments are probably maximum rates, since laboratory experiments have revealed that pellet clearance increases in the presence of an alternative food source for Eucalanus pileatus (Paffenhöfer \& Van Sant 1985), Acartia tonsa (Poulsen \& Kiørboe 2005), Calanus finmarchicus/ C. helgolandicus and Pseudocalanus elongatus (Iversen \& Poulsen unpubl. data). However, pellet clearance of Oithona similis is not influence by the presence of Thalassiosira weissflogii. In A. tonsa females, this is caused by a switch from mainly sluggish ambush feeding behavior when offered fecal pellets alone to suspension feeding when grazing a mixture of T. weissflogii and pellets (Poulsen \& Kiørboe 2005). In C. finmarchicus/C. helgolandicus and P. elongatus, the higher clearance in the presence of $T$. weissflogii is caused by increased filtration activity induced by the presence of the alga. The estimates of degradation and clearance given in the present study are therefore conservative. The low clearance rates obtained in the field-based coprophagy experiments in this study are consistent with clearance rates measured in the laboratory. Poulsen \& Kiørboe (2005) summarized available laboratory measurements of copepod fecal pellet clearance rates into a relation between clearance rate and relative fecal pellet size. Applying their relation to the present observations of copepod and fecal pellet size distributions results in estimated average fecal pellet clearance rates of 2 to $5 \mathrm{ml}$ copepod ${ }^{-1} \mathrm{~d}^{-1}$, similar to that estimated directly in the coprophagy experiments. Thus, although copepods may feed on small fecal pellets at substantial rates, the low average clearance rates estimated here are caused by the small size of the copepods relative to the larger size of the pellets present in the water column.

The fact that copepods did not seem to be important degraders of fecal pellets is surprising, since the copepod community was dominated by Oithona similis, which is thought to comprise an important part of the 'coprophagous filter' that retards vertical flux of fecal material in the water column (González \& Smetacek 1994). In this study, Oithona spp. was not collected efficiently with the $200 \mu \mathrm{m}$ net and the low degradation in the coprophagy experiments could therefore have been influenced by this. However, the Oithona spp. present in the water column were captured with an efficiency of $40 \%$ (estimated by comparing $55 \mu \mathrm{m}$ mesh size pump samples, and $200 \mu \mathrm{m}$ net samples) resulting in a relative underestimation by a factor of only 2.5 . This does not explain the 3 orders of magnitude lower degradation rate estimated from the coprophagy experiments compared to the total degradation estimated from production, abundance and sedimentation of pellets in the water column. It may be argued that the low degradation rates in the coprophagy experiments were caused by the inability of Oithona spp. to perceive the pellets hydrodynamically due to the well mixed water $(1.5 \mathrm{rpm})$ in the incubation bottles. However, after a short spin up time, there will be no turbulence in the bottles and the water would move as a solid body within the bottle (Kiørboe et al. 1999). Thus, hydrodynamic perception would not be disturbed and cannot explain the low degradation rates. Furthermore, there was no correlation between the total number of Oithona spp. and the total degradation rates during the deployments. Thus, neither Oithona spp. nor other mesozooplankters appeared to play any significant role in the degradation of copepod fecal pellets in this study, and our observations thus challenge the anticipated role of copepods in retarding the vertical flux of their own fecal pellets in the ocean. Support for the limited 
role of Oithona spp. is given by Reigstad et al. (2005), who found that, contrary to general belief, Oithona spp., do not graze Calanus spp. fecal pellets.

\section{Other factors influencing pellet degradation}

Despite the limited impact of mesozooplankton on fecal pellet degradation, we did observe substantial degradation rates, suggesting that other processes and organisms are responsible.

One important factor for pellet degradation is the size of the pellets, since smaller pellets sink slower, have longer residence time in the pelagic and are, consequently, susceptible to degradation processes for a longer time. This may be the explanation for the observed correspondence between the presence of large numbers of Oithona spp. and high degradations rates of fecal pellets in this as well as other field studies, since Oithona spp. produce small pellets. This is in accordance with Reigstadt et al. (2005), who found Oithona spp. to be an indicator species for a 'retention ecosystem' but also not the only causative agent in the system. Pellet size certainly influenced the sinking velocity and thereby also the residence time of the fecal pellets in the present study, since the substantial reduction in average pellet size that occurred subsequent to the wind event on 11 August (Fig. 5) was accordingly accompanied by a 1 order of magnitude reduction in average sinking velocity (Table 2 ). The significance of size for flux vs. retention of fecal pellets was also evident in our study area as a larger average size of pellets in the sediment traps compared to both suspended pellets and the expected average size of produced pellets (Fig. 5B), and is consistent with the general observation that larger pellets contribute most to the vertical flux of pellets (Turner \& Ferrante 1979, Lane et al. 1994).

It is therefore relevant to discuss the factors that govern the size distribution of copepod fecal pellets and, specifically, to ask what caused the abrupt change in size observed after the wind event. The shift was not caused by a shift in the species composition of the copepod community (2-way ANOVA, Tukey's HSD test) or by a shift toward younger stages since the average prosome length of the animals changed little during the study. Pellet size may be influenced by food composition (Dagg \& Walser 1986, Poulsen \& Kiørboe 2005), food quality (Dagg \& Walser 1986, Butler \& Dam 1994), food concentration (Ayukai \& Nishizawa 1986, Dagg \& Walser 1986) and ingestion rate (Dagg \& Walser 1986). While the species composition of the phytoplankton community remained relatively constant, the chl a concentration increased following the wind event. Several studies have shown that pellet size increases with increasing food concentration (Ayukai \& Nishizawa 1986, Dagg \& Walser 1986), but this is inconsistent with the observed decrease in average pellet size. However, fecal pellets produced on a flagellate diet have been observed to be smaller (Poulsen \& Kiørboe 2005) and more fragile (Hansen et al. 1996) than diatom-based pellets. The wind event induced an increase in the chl a concentration, but not a change in the species composition of the phytoplankton community. Thus, both the flagellate and diatom concentration increased after the wind event and the increased availability of food may have caused more selective feeding and a dietary shift toward flagellates. A shift toward more flagellate-based pellets may therefore be an explanation for the smaller pellets and the larger number of fragments and amorphous pellet material observed in the samples after the wind event. Fragmentation of fecal pellets, turning them into slower sinking particles, was also observed in a sediment trap study by Suzuki et al. (2003). While fragmentation may speed up fecal pellet degradation, it does not on its own recycle fecal material. Bacteria do degrade fecal pellets, but are generally not believed to be the main degraders of freshly egested fecal pellets in the sea on a time-scale of $<1 \mathrm{~d}$ (= residence time) (Jacobsen \& Azam 1984, Lampitt et al. 1990). Thus, other organisms in the plankton community, which were not retained by the $200 \mu \mathrm{m}$ net, must contribute to the degradation of the pellets. Several smaller plankton organisms have been reported to degrade fecal pellets. Kiørboe (2003) found high clearance rates $\left(\sim 600 \mathrm{ml} \mathrm{cell}^{-1} \mathrm{~d}^{-1}\right)$ of Noctiluca scintillans on fecal pellets in an upwelling plume off the coast of Brazil. N. scintillans was observed in the plankton in the present study but not counted. Nauplii of hapacticoid copepods, which may be very abundant in the pelagic, may consume fecal pellets at specific hourly rates corresponding to their own body weight (Koski et al. 2005). Furthermore, ciliates and heterotrophic flagellates may colonize fecal pellets and have been observed to increase pellet degradation (Hansen et al. 1996), and microscopic observations by Lampitt et al. (1990) suggest that ciliates can cause substantial physical damage to the pellet when the periothrophic membrane has been removed. Finally, small and fragmented fecal pellets become available to fine-particle feeders such as protozoans and appendicularians (Paffenhöfer \& Knowles 1979). The present study clearly indicates that the role of heterotrophic microplankton needs to be investigated further to better understand the processes by which fecal pellets are degraded in the ocean.

Acknowledgements. We thank the captain and crew on the RV 'Dana', and the participating scientists and technicians for their help during the cruise, particularly Morgens Busse, 
Marja Koski and Nguyen Huu Trung. We also thank Sofia Hammami for counting the samples. L.K.P. was supported by the SLIP research school under the Danish Network for Fisheries and Aquaculture Research financed by the Danish Ministry for Food, Agriculture, and Fisheries and the Danish Agricultural and Veterinary Research Council, and T.K. by a grant from the Danish Natural Science Research Council (\#21-01-0549).

\section{LITERATURE CITED}

Ayukai T, Nishizawa S (1986) Defecation rate as a possible measure of ingestion rate of Calanus pacificus pacificus (Copepoda: Calanoida). Bull Plankton Soc Jpn 33:3-10

Butler M, Dam HG (1994) Production rates and characteristics of fecal pellets of the copepod Acartia tonsa under simulated phytoplankton bloom conditions: implications for vertical fluxes. Mar Ecol Prog Ser 114:81-91

Dagg MJ, Walser WE (1986) The effect of food concentration on fecal pellet size in marine copepods. Limnol Oceanogr 31:1066-1071

Edler L (1979) Recommendations for marine biological studies in the Baltic Sea - phytoplankton and chlorophyll. Baltic Mar Biol 5:1-38

González HE, Smetacek V (1994) The possible role of the cyclopoid copepod Oithona in retarding vertical flux of zooplankton faecal material. Mar Ecol Prog Ser 113:233-246

González HE, González SR, Brummer GJA (1994a) Shortterm sedimentation pattern of zooplankton, faeces and microplankton at a permanent station in the Bjørnafjorden (Norway) during April-May 1992. Mar Ecol Prog Ser 105: $31-45$

González HE, Kurbjeweit K, Bathmann UV (1994b) Occurrence of cyclopoid copepods and faecal material in the Halley Bay region, Antarctica, during January-February 1991. Polar Biol 14:331-342

Hansen B, Fotel FL, Jensen NJ, Madsen SD (1996) Bacteria associated with a marine planktonic copepod in culture. II. Degradation of fecal pellets produced on a diatom, a nanoflagellate or a dinoflagellate diet. J Plankton Res 18: 275-288

Jacobsen TR, Azam F (1984) Role of bacteria in copepod fecal pellet decomposition: colonization, growth rates and mineralization. Bull Mar Sci 35:495-502

Kiørboe T (2003) High turnover rates of copepod fecal pellets due to Noctiluca scintillans grazing. Mar Ecol Prog Ser 258:181-188

Kiørboe T, Saiz E, Visser A (1999) Hydrodynamic signal perception in the copepod Acartia tonsa. Mar Ecol Prog Ser 179:97-111

Koski M, Kiørboe T, Takahashi K (2005) Benthic life in the pelagial: aggregate encounter and degradation rates by pelagic harpacticoids. Limnol Oceanogr 50:1254-1263

Lampitt RS, Noji TT, Von Bodungen B (1990) What happens to zooplankton faecal pellets? Implications for material flux. Mar Biol 104:15-23

Lane PVZ, Smith SL, Urban JL, Biscaye PE (1994) Carbon flux and recycling associated with zooplanktonic fecal pellets on the shelf of the Middle Atlantic Bight. Deep-Sea Res II 41:437-457

Editorial responsibility: Otto Kinne (Editor-in-Chief), Oldendorf/Luhe, Germany
Martens P, Krause M (1990) The fate of faecal pellets in the North Sea. Helgol Meeresunters 44:9-19

Møhlenberg F (1987) A submersible net-pump for quantitative zooplankton sampling; comparison with conventional net sampling. Ophelia 27:101-110

Noji TT, Estep KW, MacIntyre F, Norrbin F (1991) Image analysis of faecal material grazed upon by three species of copepods: evidence for coprorhezy, coprophagy and coprochaly. J Mar Biol Assoc UK 71:465-480

Olesen M (2001) Sedimentation in Mariager Fjord, Denmark: the impact of sinking velocity on system productivity. Ophelia 55:11-26

Paffenhöfer GA, Knowles SC (1979) Ecological implications of fecal pellet size, production and consumption by copepods. J Mar Res 3:35-49

Paffenhöfer GA, Strickland JDH (1970) A note on the feeding of Calanus helgolandicus on detritus. Mar Biol 5:97-99

Paffenhöfer GA, Van Sant KB (1985) The feeding response of a marine planktonic copepod to quantity and quality of particles. Mar Ecol Prog Ser 27:55-65

Peterson W, Dam HG (1990) The influence of copepod 'swimmers' on pigment fluxes in brine-filled vs. ambient seawater-filled sediment traps. Limnol Oceanogr 35: $448-455$

Poulsen LK, Kiørboe T (2005) Coprorhexy and coprophagy in the copepods Acartia tonsa and Temora longicornis: clearance rate and feeding behaviour. Mar Ecol Prog Ser 299: $217-227$

Reigstad M, Riser CW, Svensen C (2005) Fate of copepod faecal pellets and the role of Oithona spp. Mar Ecol Prog Ser 304:265-270

Roman MR, Gauzens AL (1997) Copepod grazing in the equatorial Pacific. Limnol Oceanogr 42:623-634

Sampei M, Sasaki H, Hattori H, Fukuchi M, Hargrave BT (2004) Fate of sinking particles, especially fecal pellets, within the epipelagic zone in the North Water (NOW) polynya of northern Baffin Bay. Mar Ecol Prog Ser 278: $17-25$

Smetacek VS (1980) Zooplankton standing stock, copepod faecal pellets and particulate detritus in Kiel Bight. Estuar Coast Mar Sci 11:477-490

Suzuki H, Sasaki H, Fukuchi M (2003) Loss processes of sinking fecal pellets of zooplankton in the mesopelagic layers of the Antarctic Marginal Ice Zone. J Oceanogr 59: 809-818

Svensen C, Nejstgaard JC (2003) Is sedimentation of copepod faecal pellets determined by cyclopoids? Evidence from enclosed ecosystems. J Plankton Res 25:917-926

Turner JT (2002) Zooplankton fecal pellets, marine snow and sinking phytoplankton blooms. Aquat Microb Ecol 27: 57-102

Turner JT, Ferrante JG (1979) Zooplankton fecal pellets in aquatic ecosystems. BioScience 29:670-677

Viitasalo M, Rosenberg M, Heiskanen A, Koski M (1999) Sedimentation of copepod fecal material in the coastal northern Baltic Sea: where did all the pellets go? Limnol Oceanogr 44:1388-1399

Wassmann P, Ypma JE, Tselepides A (2000) Vertical flux of faecal pellets and microplankton on the shelf of the oligotrophic Cretan Sea (NE Mediterranean Sea). Prog Oceanogr 46:241-258

Submitted: January 25, 2005; Accepted: March 7, 2006

Proofs received from author(s): September 18, 2006 